\title{
Effect of Herbal Alternative Irrigant (Green Tea Polyphenols) on the Microhardness of Root Canal Dentin after Instrumentation with Thermomechanically Treated NiTi Instruments: An in vitro Study
}

\author{
${ }^{1}$ Nikhil Murali, ${ }^{2}$ B Jyothi Lekshmi, ${ }^{3}$ Iqbal Sha, ${ }^{4}$ Rajesh Pillai, ${ }^{5}$ Nettiyat O Varghese, ${ }^{6}$ Abdul S Afzal
}

\begin{abstract}
Introduction: The aim of this study is to evaluate the effects of herbal alternative (green tea polyphenols) and ethylenediaminetetraacetic acid (EDTA) $+\mathrm{NaOCl}$ on the microhardness of root canal dentin after instrumentation with ProTaper Next (PTN; Dentsply) and Twisted Files (TF; SybronEndo).

Materials and methods: Twenty single-rooted human premolar teeth will be instrumented up to the working length with PTN and TF (10 each) and then will be longitudinally sectioned into 40 segments and then embedded in an autopolymerizing acrylic resin. The microhardness of the dentin in the specimen will be measured with a Vickers diamond indenter at the apical third of the roots. Then the specimens will be divided randomly into two groups: $17 \%$ EDTA $+2.5 \% \mathrm{NaOCl}$ and green tea polyphenols. Posttreatment microhardness values will be obtained and the decrease in microhardness will be calculated as a percentage. Microhardness values will be statistically analyzed using the Kruskal-Wallis and Mann-Whitney $U$ tests.
\end{abstract}

Results: Statistical analysis using one-way analysis of variance (ANOVA) showed that both the file groups with $\mathrm{NaOCl}+$ EDTA showed significant reduction in root dentin microhardness $(p>0.05)$.

Conclusion: Even though green tea polyphenols showed lesser reduction in microhardness, its ability to remove smear layer completely and the antibacterial efficacy and practicality of using green tea as a root canal irrigant require further investigations. Its potency to discolor tooth and ability to eliminate biofilm is a matter of debate.

Keywords: Green tea polyphenol, Microhardness, ProTaper Next, Root canal dentin, Twisted File.

How to cite this article: Murali N, Lekshmi BJ, Sha I, Pillai R, Varghese NO, Afzal AS. Effect of Herbal Alternative Irrigant (Green Tea Polyphenols) on the Microhardness of Root Canal

\footnotetext{
${ }^{1-3}$ Postgraduate Student, ${ }^{4}$ Professor and Head, ${ }^{5}$ Prinicipal ${ }^{6}$ Professor

${ }^{1}$ Department of Conservative Dentistry, PMS College of Dental Science \& Research, Thiruvananthapuram, Kerala, India

${ }^{2-6}$ Department of Conservative Dentistry and Endodontics, PMS College of Dental Science \& Research, Thiruvananthapuram Kerala, India

Corresponding Author: Nikhil Murali, Postgraduate Student Department of Conservative Dentistry, PMS College of Dental Science \& Research, Thiruvananthapuram, Kerala, India Phone: +919895029365, e-mail: nikhilmurali@gmail.com
}

Dentin after Instrumentation with Thermomechanically Treated NiTi Instruments: An in vitro Study. Cons Dent Endod J 2018; $3(1): 11-16$

Source of support: Nil

Conflict of interest: None

\section{INTRODUCTION}

The aim of pulp space therapy is not only to eliminate infection within pulp space but also to prevent reinfection. Elimination of all bacteria and debris is impossible because of the anatomic complexity of pulp space. ${ }^{1}$ Thus the use of irrigating solution is mandated in order to improve cleaning and shaping by minimizing the residual debris, necrotic tissue, and bacteria and removing the smear layer formed after shaping. ${ }^{2}$

Over the years, plethora of irrigating solutions are available to the endodontists ranging from a stream of hot water discharged from an insulated syringe, physiological saline solution, 30\% solution of urea, urea peroxide solution in glycerin, $\mathrm{NaOCl}$, and $\mathrm{NaOCl}$ in conjunction with EDTA, etc.

There is a constant increase in antibiotic strains. Synthetic drugs have got various adverse effects and it promoted researchers to innovate herbal alternatives like Morinda citrifolia juice along with EDTA, Triphala, aloe vera, propolis, green tea, and various other agents. ${ }^{3}$ Green tea polyphenols have been prepared from young shoots of tea plant Camellia sinensis. ${ }^{4}$ Green tea exhibits antibacterial activity on Enterococcus faecalis pyknotic cells. It also revealed its excellent chelating properties. ${ }^{5}$ These irrigants and chelating agents may cause changes in the microstructure of dentin and in the ratio of calcium to phosphorous. ${ }^{6}$ Panighi and $\mathrm{G}^{\prime}$ Sell ${ }^{7}$ have reported a positive correlation between mineral content of the tooth and mechanical and physical properties of dentin, i.e., microhardness, permeability, solubility.

A decrease in microhardness can affect the ability of sealers to effectively adhere to and seal the dentinal walls of pulp space. ${ }^{7}$ Twisted File (SybronEndo, Orange, California, USA) is a recent innovation to nickel-titanium (NiTi) rotary file system. It is a combination of three features, namely R-phase heat treatment, manufacturing by twisting the metal, and special surface conditioning. ${ }^{8}$ 
Twisted Files have been manufactured using twisting process rather than grinding. Previous studies demonstrated that TF showed higher resistance to cyclic fatigue. As well, they removed dentin more efficiently and in a uniform manner. ${ }^{9,10}$ Progressive percentage tapers on a single file, M-wire technology, the fifth generation of continuous improvement, and the offset design are unique features of PTN. ${ }^{11}$ Fusayama and Maeda ${ }^{12}$ reported that as compared with vital teeth, pulpless teeth showed reduction in microhardness. A similar correlation can be made between microhardness of root dentin and irrigation solutions. ${ }^{12}$

The purpose of this study was to determine the root dentin microhardness after instrumentation with two different thermomechanically treated NiTi rotary files used alternatively with two different irrigants and to compare the above combination in altering the root dentin microhardness.

\section{MATERIALS AND METHODS}

Twenty extracted human mandibular single-rooted premolar teeth devoid of any cracks, caries, developmental defects, and regressive changes were selected.
Radiographs were taken in buccolingual and mesiodistal angulation to verify the presence of single root canal. Teeth were then decoronated using a diamond disk at the level of cement enamel junction to obtain a standardized length of $15 \mathrm{~mm}$ (Fig. 1). Teeth were then randomly divided into four groups $(\mathrm{n}=5)$. Working length was established by inserting a 25-mm, size $15 \mathrm{~K}$ file into the root canal until it was seen at the apical foramen. One millimeter was subtracted from this length and was taken as the working length. In 10 teeth root canal were prepared using PTN up to X2 (25.06) and next 10 teeth were prepared using TF up to 25 (06) (Fig. 2). During instrumentation the canals were irrigated with $2 \mathrm{~mL}$ of $2.5 \% \mathrm{NaOCl}$ at each change of file. Each root was then sectioned longitudinally using a diamond disk from cervical to apical area (Fig. 3) and the dentinal surface were smoothened with ascending grades of silicon carbide abrasive papers. Specimens were embedded horizontally in autopolymerizing acrylic resin, and then subjected to immersion treatment (Fig. 4).

\section{Preparation of Green Tea Extracts}

A total of $120 \mathrm{gm}$ of pure green tea was mixed with $5 \mathrm{~mL}$ of $10 \%$ dimethyl sulfoxide (DMSO) liquid. To improve

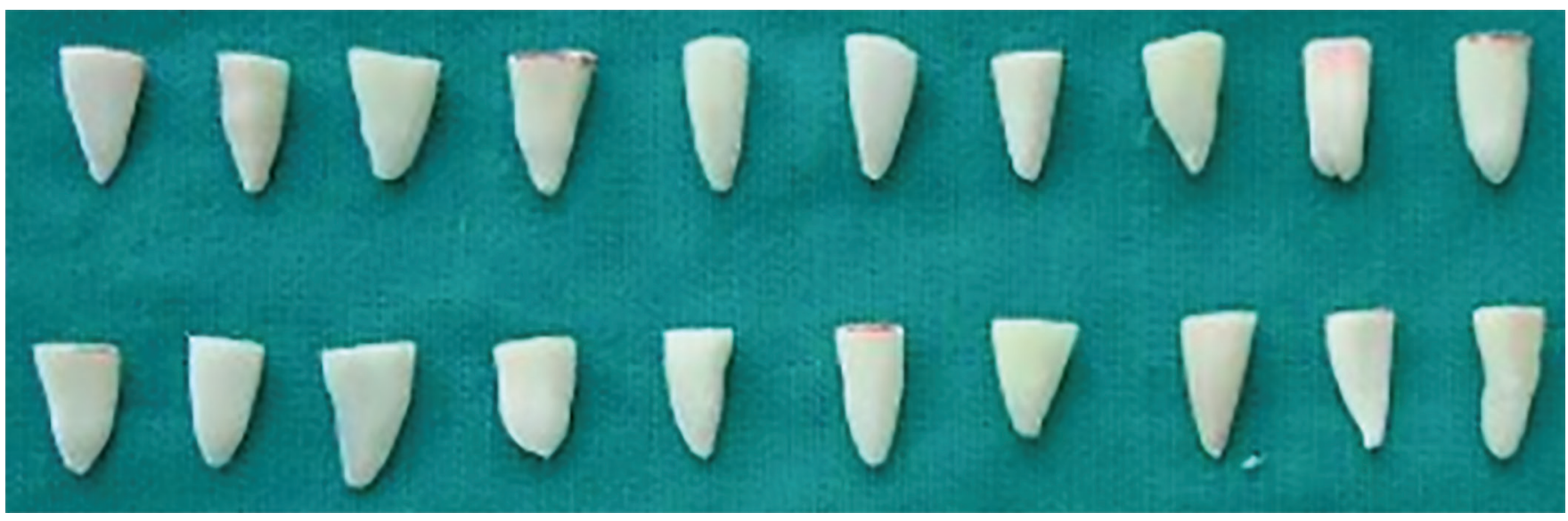

Fig. 1: Decoronated samples

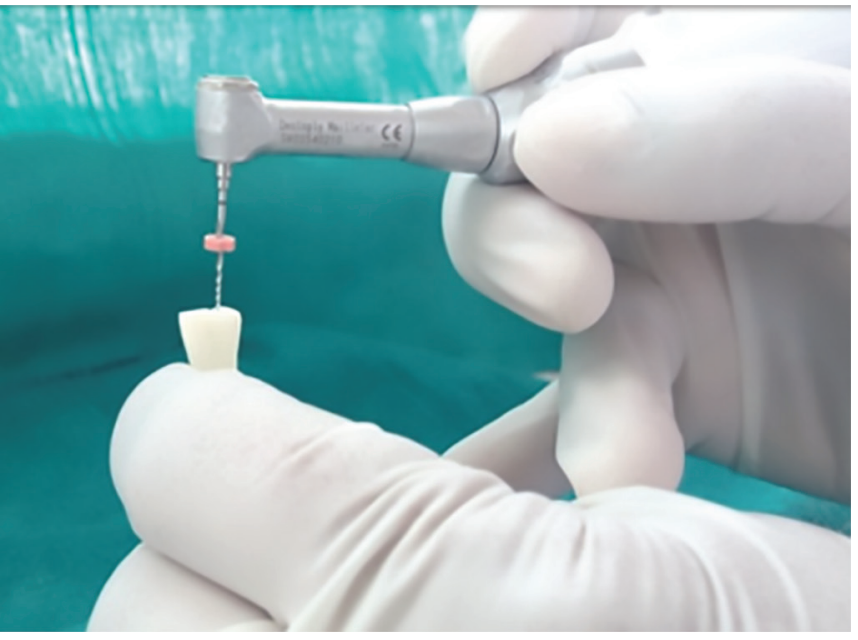

Fig. 2: Root canal preparation

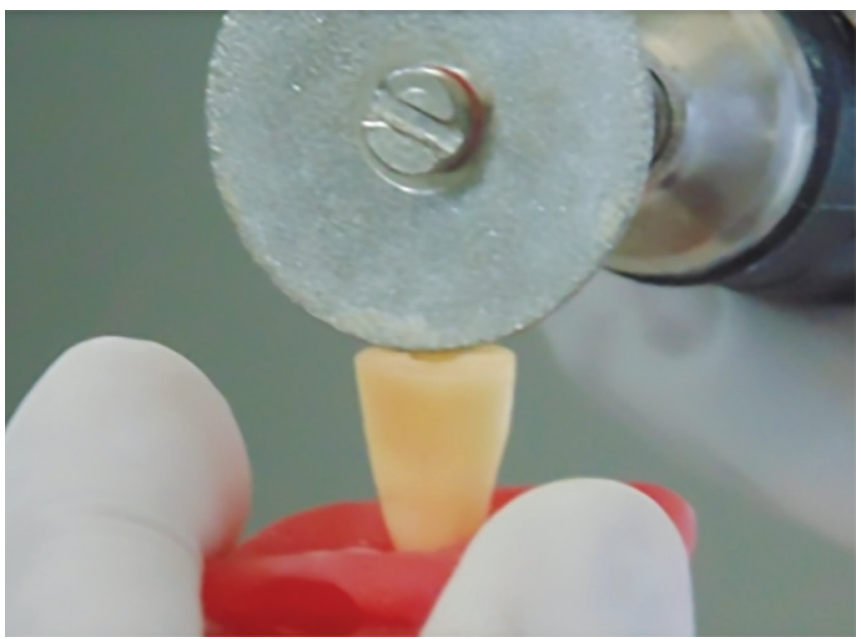

Fig. 3: Longitudinal sectioning of samples 


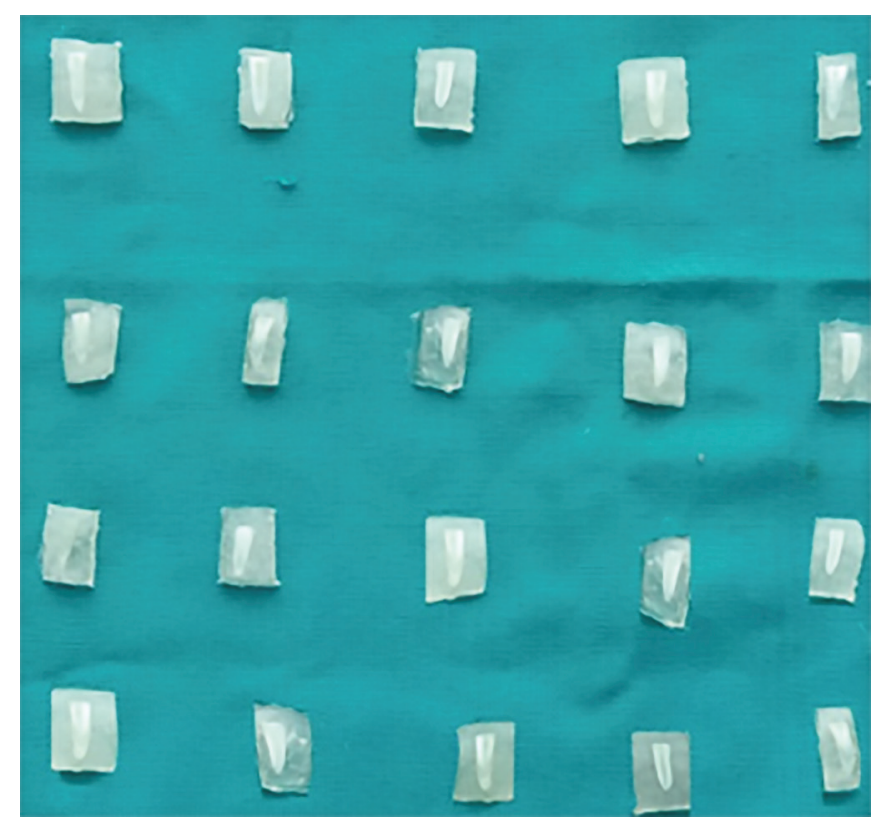

Fig. 4: Specimens embedded in acrylic resin blocks

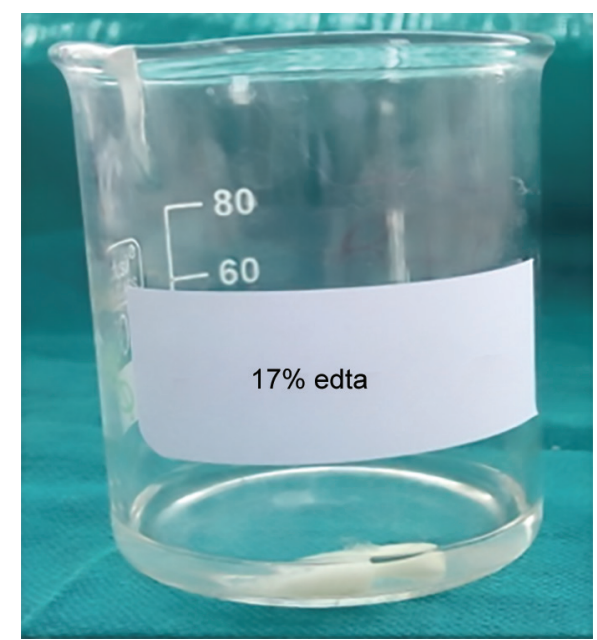

Fig. 6: 17\% EDTA

the efficiency of herbal products, DMSO has been added. Before the immersion treatment, dentin microhardness values were measured with the Vickers diamond indenter with a $50 \mathrm{~g}$ force for 14 seconds duration at the apical dentin oriented perpendicular to the surface. The locations were chosen parallel to the edge of the root canal lumen, at a depth of $100 \mu \mathrm{m}$ from the pulp-dentin interface in the apical third of the roots:

- Group I samples were immersed in $5 \mathrm{~mL} 3 \% \mathrm{NaOCl}$ (Asian Acrylates, Mumbai, India) (Fig. 5) followed by 17\% EDTA (Smear Clear) (Fig. 6) for 1 minute (PTN).

- Group II samples were immersed in $5 \mathrm{~mL}$ green tea polyphenol (K Patel Pvt Ltd, India) $(60 \mathrm{mg} / \mathrm{mL}$ in $10 \%$ DMSO) for 1 minute (PTN) (Fig. 7).

- Group III samples were immersed in $5 \mathrm{~mL} 3 \% \mathrm{NaOCl}$ (Asian Acrylates, Mumbai, India) followed by $17 \%$ EDTA for 1 minute (TF).

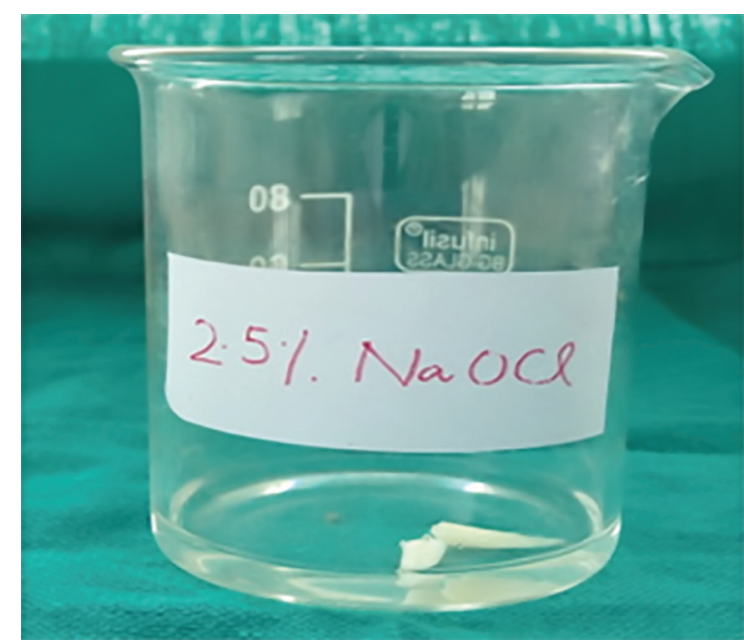

Fig. 5: $2.5 \% \mathrm{NaOCl}$

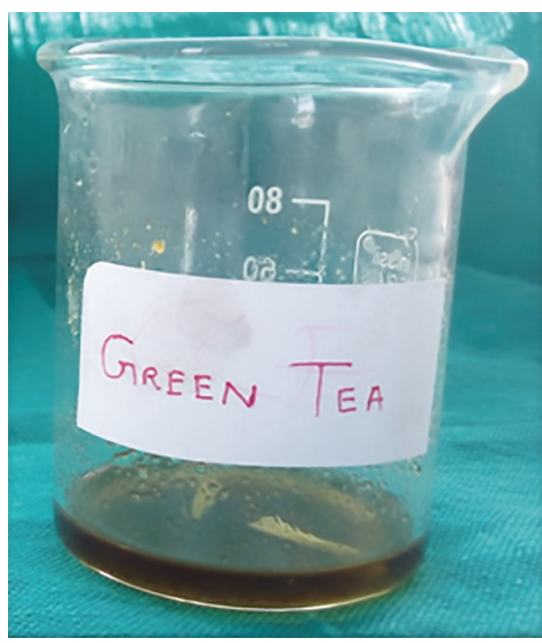

Fig. 7: Green tea

- Group IV samples were immersed in $5 \mathrm{~mL}$ green tea polyphenol (K Patel Pvt Ltd, India) $(60 \mathrm{mg} / \mathrm{mL}$ in $10 \%$ DMSO) for 1 minute (TF).

After immersion the specimens were rinsed immediately with saline to avoid prolonged effects of chelating solutions. New indentations were made on each specimen adjacent to the initial ones using the same method utilized previously, and the microhardness values recorded (Table1) using universal testing machine (Fig. 8).

Microhardness values were statistically analyzed using the Kruskal-Wallis and Mann-Whitney U test.

\section{RESULTS AND STATISTICAL ANALYSIS}

Statistical analysis using one-way ANOVA showed that both the file groups with $\mathrm{NaOCl}+$ EDTA showed significant reduction in root dentin microhardness $(p>0.05)$ (Graph 1). Green tea group did not decrease the microhardness values significantly $(p<0.05)$. There was also no significant difference between both the file systems with respect to change in microhardness even 


\begin{tabular}{lcllll}
\hline \multicolumn{5}{c}{ Table 1: Pretreatment and posttreatment microhardness mean value } \\
\hline & $n$ & Pretreatment & Posttreatment & Standard & Standard \\
deviation pre & deviation post \\
Test group & 5 & 51.11 & 42.82 & 6.64002 & 5.81287 \\
PTN 2.5\% NaOCl + 17\% EDTA & 5 & 51.04 & 47.23 & 7.13822 & 7.02765 \\
PTN-Green tea & 5 & 48.94 & 40.37 & 1.06196 & 1.00912 \\
TF-2.5\% NaOCl + 17\% EDTA & 5 & 48.78 & 43.59 & 3.31881 & 2.99811 \\
TF-Green tea & & & &
\end{tabular}

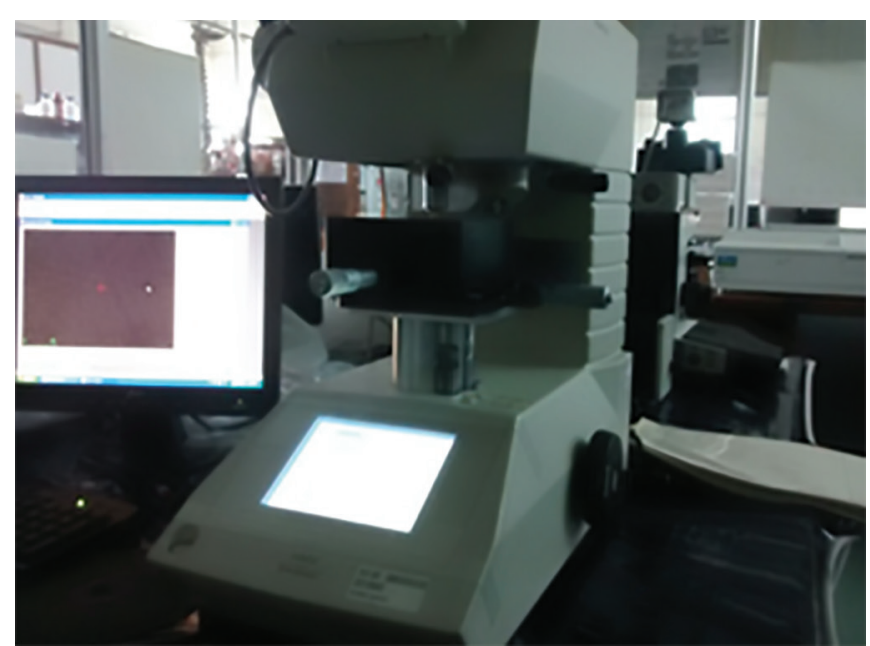

Fig. 8: Microhardness testing using universal testing machine

though TF in both the groups reduced more dentin as compared with PTN.

\section{DISCUSSION}

In the past, the effect of irrigation solutions on the microhardness of root canal dentin has been evaluated in several in vitro studies by using roots sectioned transversally into dentin disks, or split longitudinally. ${ }^{13-15}$ The hardness value in the region between the main canal and the cementum layer in the dentin disks specimen was evaluated. However, in clinical situations, irrigants first contact the most superficial layer of dentin in the root canal lumen. Cruz-Filho et al ${ }^{14}$ observed that more accurate representations of clinical situations are observed in studies in which the roots were split longitudinally instead of cut transversally into disks. Bearing this in mind, the microhardness of the most superficial layer of root canal dentin has been evaluated in the present study measures. The microhardness of dentin depends on the physical properties of the solution (i.e., $\mathrm{pH}$ and concentration) and structure of dentin (i.e., tubular density, location, age).

The diameter and number of dentinal tubules also plays a significant role in the effectiveness of irrigants. ${ }^{16,17}$ Pashley et a $1^{18}$ reported that the microhardness decreases from superficial to deep dentin regions. Oliveira et $\mathrm{al}^{19}$ evaluated microhardness values of root dentin at 500 and

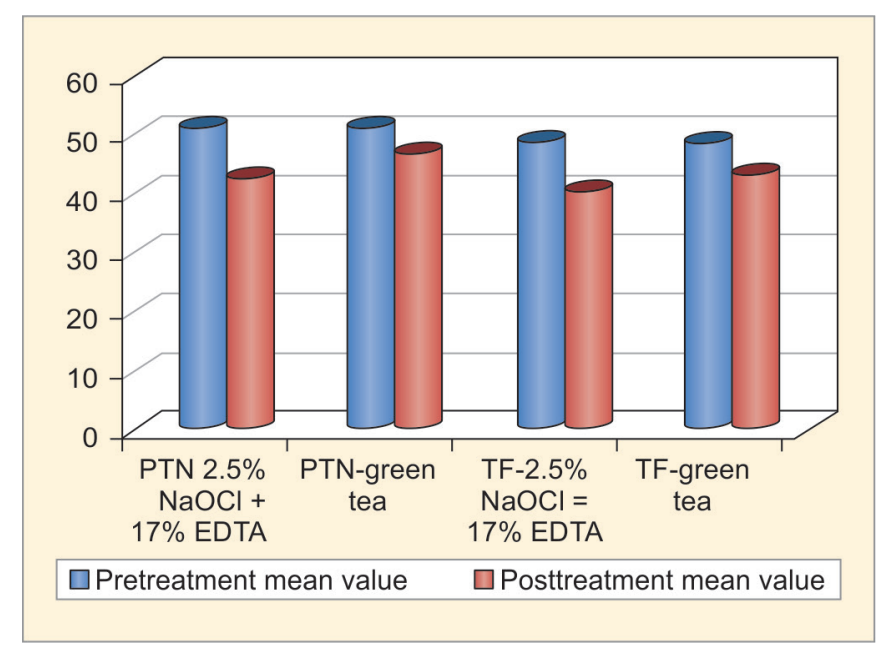

Graph 1: Comparison between different groups regarding the overall percentage decrease in microhardness

$1000 \mu \mathrm{m}$ from the pulp-dentin interface and found that dentin microhardness depends on location and its values decreased as the indentations moved closer to the pulp.

Dentinal tubules near the pulp offer little resistance to the testing indenter because they are more numerous, wider in diameter, and free of peritubular dentin. ${ }^{12}$ Therefore, in the current study, for the purpose of standardization, indentations were made $100 \mu \mathrm{m}$ from the pulp-dentin interface. The application time of irrigants is also another important factor. ${ }^{20}$ Currently, there is no consensus about the optimum application time of irrigants to adequately remove the smear layer.

As performed in the current study, Calt and Serper ${ }^{21}$ reported that $17 \%$ EDTA irrigation for 1 minute is effective in the removal of smear layer. Extended application times of EDTA may increase calcium removal from root dentin, ${ }^{17}$ resulting in tubular erosion..$^{22}$ In the infected canal, the most critical area is the apical $3 \mathrm{~mm}$, which harbors a large amount of microorganisms. Also, it has better accessibility to periapical tissue.

This would help them to not only acquire nutrition but also exert harmful effects on the surrounding structures. ${ }^{23}$ Hence, thorough instrumentation and irrigation of the apical portion is critical, and hence, in this study apical root dentin was chosen for testing microhardness. Oliveira et $\mathrm{al}^{19}$ have addressed the reliability of Vickers microhardness test in the evaluation of surface changes of dentin treated with chemical agents. 
For this reason, the Vickers microhardness test was used in the current study to evaluate the superficial layer of dentin of the root canal lumen. Both the file groups with $\mathrm{NaOCl}+$ EDTA showed significant reduction in root dentin microhardness in the current study. Various studies have showed that the reason for dentinal erosion on the root canal wall is the hyperdecalcification effect of EDTA. ${ }^{21,24}$ When EDTA alone is used for irrigation, the organic matrix of dentin acts as a limiting factor for its dissolution because it accumulates on the canal surface, preventing further dissolution. ${ }^{25} \mathrm{Niu}$ et $\mathrm{al}^{24}$ concluded that final irrigation with $\mathrm{NaOCl}$ accelerates dentinal erosion following the treatment with EDTA. Recently, Qian et $\mathrm{al}^{26}$ showed that if $\mathrm{NaOCl}$ is used again after EDTA or citric acid, as the final antibacterial rinse, it causes a marked erosion of the radicular wall dentin.

This result augments well with the present study. However, in both the green tea groups, the difference between pre- and posttreatment microhardness values are less when compared with the $\mathrm{NaOCl-EDTA}$ group. $\mathrm{NaOCl}$ is a halogenated compound, having antiseptic ability, and low surface tension. It partially neutralizes the toxic products and dissolves organic tissue. ${ }^{27} \mathrm{But}$, it does not act on the inorganic portion of dentin, which is a major constituent of the smear layer. ${ }^{27}$ EDTA, with its softening effect on dentinal walls, helps in instrumentation. It has an excellent ability in removing smear layer. ${ }^{27}$ The association of both NaOCl-EDTA is largely used in endodontic therapy as they act simultaneously in organic and inorganic portion of dentin, thereby making the instrumentation process more efficient. ${ }^{27}$ Major component of green tea extracts (GTEs) is catechin, which is one of the polyphenols from green tea. ${ }^{28}$ Several studies have shown that GTEs have remarkable antiinflammatory, antioxidant, and anticarcinogenic effects in a number of animal tumors, cell culture systems, and epidemiological studies. ${ }^{29}$ Study done by Prabhakar et $\mathrm{al}^{5}$ have found out that green tea polyphenols is a remarkable chelating agent.

Green tea catechins have the ability to affect absorption and metabolism of ions as flavonoids interact with a variety of metal ions. ${ }^{30}$ The purpose of using two different files systems was to check whether M-wire with offset design and TF with R-phase would actually have any effect on decreasing the stresses on apical one-third.

In this study, PTN showed lesser reduction in microhardness value as compared with TF; maybe because of the fact that PTN files have been designed such that the center of mass and/or the center of rotation are offset. In rotation, files having an offset design create a swaggering wave of motion. It travels along the active length of the file.
The patented design's axis of rotation differs from the center of mass. As a result, only two points of the rectangular cross section do touch the canal walls at a time. Offset design of PTN minimizes the engagement of file with the dentin. ${ }^{11}$ There were some limitations in the present study. The experimental conditions of the immersion tests differed substantially from actual clinical situations.

In clinical situations, the root canal is a closed-end channel, and this produces a vapor lock effect during irrigation. As a result, different parts of the root canal wall are affected differently by irrigation, especially in the apical third. In the tests, however, it is possible to evenly apply a relatively large amount of the irrigant so that it remains in close contact with the dentin surface.

This is not the case in clinical situations. Further studies have to be done to analyze the adverse effect of irrigants in conjunction with agitation devices, such as sonic and ultrasonic agitation systems.

\section{CONCLUSION}

Developing an ideal file system-irrigation regimen combination which would effectively remove smear layer, debris, and microorganism but at the same time preserve tooth structure is mandated. Even though green tea polyphenols showed lesser reduction in microhardness, its ability to remove smear layer completely and the antibacterial efficacy and practicality of using green tea as a root canal irrigant requires further investigations. M-wire with offset design do have pronounced merits over R-phase technology in this present study.

\section{CLINICAL SIGNIFICANCE}

Although a reduction in microhardness facilitates easy instrumentation in the root canal, it may also weaken the root structure. Microhardness determination provides evidence for losing or gaining any mineral substance in the dental hard tissue.

\section{REFERENCES}

1. Hülsmann $M$, Heckendorff $M$, Lennon A. Chelating agents in root canal treatment: mode of action and indications for their use. Int Endod J 2003 Dec;36(12):810-830.

2. Siqueira JF Jr, Lima KC, Magalhães FA, Lopes HP, de Uzeda M. Mechanical reduction of the bacterial population in the root canal by three instrumentation techniques. J Endod 1999 May;25(5):332-335.

3. Murray PE, Farber RM, Namerow KN, Kuttler S, GarciaGodoy F. Evaluation of Morinda citrifolia as an endodontic irrigant. J Endod 2008 Jan;34(1):66-70.

4. Taylor PW, Hamilton-Miller JM, Stapleton PD. Antimicrobial properties of green tea catechins. Food Sci Technol Bull 2005;2:71-81. 
5. Prabhakar J, Senthilkumar M, Priya MS, Mahalakshmi K, Sehgal PK, Sukumaran VG. Evaluation of antimicrobial efficacy of herbal alternatives (Triphala and Green tea polyphenols), MTAD and 5\% sodium hypochloride against Enterococcus faecalis biofilm formed on tooth substrate: an in vitro study. J Endod 2010 Jan;36(1):83-86.

6. Dogan $\mathrm{H}, \mathrm{Calt} \mathrm{S}$. Effects of chelating agents and sodium hypochlorite on mineral content of root dentin. J Endod 2001 Sep;27(9):578-880.

7. Panighi M, G'Sell C. Effect of the tooth microstructure on the shear bond strength of a dental composite. J Biomed Mater Res 1993 Aug;27(8):975-981.

8. Gambarini G, Grande NM, Plotino G, Somma F, Garala M, De Luca M, Testarelli L. Fatigue resistance of engine-driven rotary nickel-titanium instruments produced by new manufacturing methods. J Endod 2008 Aug;34(8):1003-1005.

9. Kim HC, Yum J, Hur B, Cheung GS. Cyclic fatigue and fracture characteristics of ground and twisted nickel-titanium rotary files. J Endod 2010 Jan;36(1):147-152.

10. Larsen CM, Watanabe I, Glickman GN, He J. Cyclic fatigue analysis of a new generation of nickel titanium rotary instruments. J Endod 2009 Mar;35(3):401-403.

11. Ruddle CJ, Machtou P, West JD. The shaping movement: fifth-generation technology. Dent Today 2013 Apr;32(4):94, 96-99.

12. Fusayama T, Maeda T. Effect of pulpectomy on dentin hardness. J Dent Res 1969 May-Jun;48(3):452-460.

13. Ballal NV, Mala K, Bhat KS. Evaluation of the effect of maleic acid and ethylenediaminetetraacetic acid on the microhardness and surface roughness of human root canal dentin. J Endod 2010 Aug;36(8):1385-1388.

14. Cruz-Filho AM, Sousa-Neto MD, Savioli RN, Silva RG, Vansan LP, Pecora JD. Effect of chelating solutions on the microhardness of root canal lumen dentin. J Endod 2011 Mar;37(3):358-362.

15. Saghiri MA, Delvarani A, Mehrvarzfar P, Malganji G, Lotfi M, Dadresanfar B, Saghiri AM, Dadvand S. A study of the relation between erosion and microhardness of root canal dentin. Oral Surg Oral Med Oral Pathol Oral Radiol Endod 2009 Dec;108(6):e29-e34.

16. Zhang K,Kim YK, Cadenaro M, Bryan TE,Sidow SJ,Loushine RJ, Ling JQ, Pashley DH, Tay FR. Effects of different exposure times and concentrations of sodium hypochlorite/ethylenediaminetetraacetic acid on the structural integrity of mineralized dentin. J Endod 2010 Jan;36(1):105-109.

17. Sayin TC, Serper A, Cehreli ZC, Kalayci S. Calcium loss from root canal dentin following EDTA, EGTA, EDTAC, and tetracycline- $\mathrm{HCl}$ treatment with or without subsequent $\mathrm{NaOCl}$ irrigation. J Endod 2007 May;33(5):581-584.

18. Pashley D, Okabe A, Parham P. The relationship between dentin microhardness and tubule density. Endod Dent Traumatol 1985 Oct;1(5):176-179.

19. Oliveira LD, Carvalho CA, Nunes W, Valera MC, Camargo CH, Jorge AO. Effects of chlorhexidine and sodium hypochlorite on the microhardness of root canal dentin. Oral Surg Oral Med Oral Pathol Oral Radiol Endod 2007 Oct;104(4):e125-e128.

20. Akcay I, Sen BH. The effect of surfactant addition to EDTA on microhardness of root dentin. J Endod 2012 May;38(5): 704-707.

21. Calt S, Serper A. Time-dependent effects of EDTA on dentin structures. J Endod 2002 Jan;28(1):17-19.

22. Ulusoy OI, Gorg G. Effects of different irrigation solutions on root dentine microhardness, smear layer removal and erosion. Aust Endod J 2013 Aug;39(2):66-72.

23. Alothmani OS, Chandler NP, Friedlander LT. The anatomy of the root apex: a review and clinical considerations in endodontics. Saudi Endod J 2013 Aug;3(1):1-9.

24. Niu W, Yoshioka T, Kobayashi C, Suda H. A scanning electron microscopic study of dentinal erosion by final irrigation with EDTA and NaOCl solutions. Int Endod J 2002 Nov;35(11): 934-939.

25. Oyarzun A, Cordero AM, Whittle M. Immunohistochemical evaluation of the effects of sodium hypochlorite on dentin collagen and glycosaminoglycans. J Endod 2002 Mar;28(3): 152-156.

26. Qian W, Shen Y, Haapasalo M. Quantitative analysis of the effect of irrigant solution sequences on dentin erosion. J Endod 2011 Oct;37(10):1437-1441.

27. Cecchin D, Farina AP, Galafassi D, Barbizam JV, Corona SA, Carlini-Júnior B. Influence of sodium hypochlorite and EDTA on the microtensile bond strength of a self-etching adhesive system. J Appl Oral Sci 2010 Jul-Aug;18(4):385-389.

28. Dreosti IE. Bioactive ingredients: antioxidants and polyphenols in tea. Nutr Rev 1996 Nov;54(11 Pt 2):S51-S58.

29. Elbling L, Weiss RM, Teufelhofer O, Uhl M, Knasmueller S, Schulte-Hermann R, Berger W, Micksche M. Green tea extract and (-)-epigallocatechin-3-gallate, the major tea catechin, exert oxidant but lack antioxidant activities. FASEB J 2005 May;19(7):807-809.

30. Mira L, Fernandez MT, Santos M, Rocha R, Florencio MH, Jennings KR. Interactions of flavonoids with iron and copper ions: a mechanism for their antioxidant activity. Free Radic Res 2002 Nov;36(11):1199-1208. 